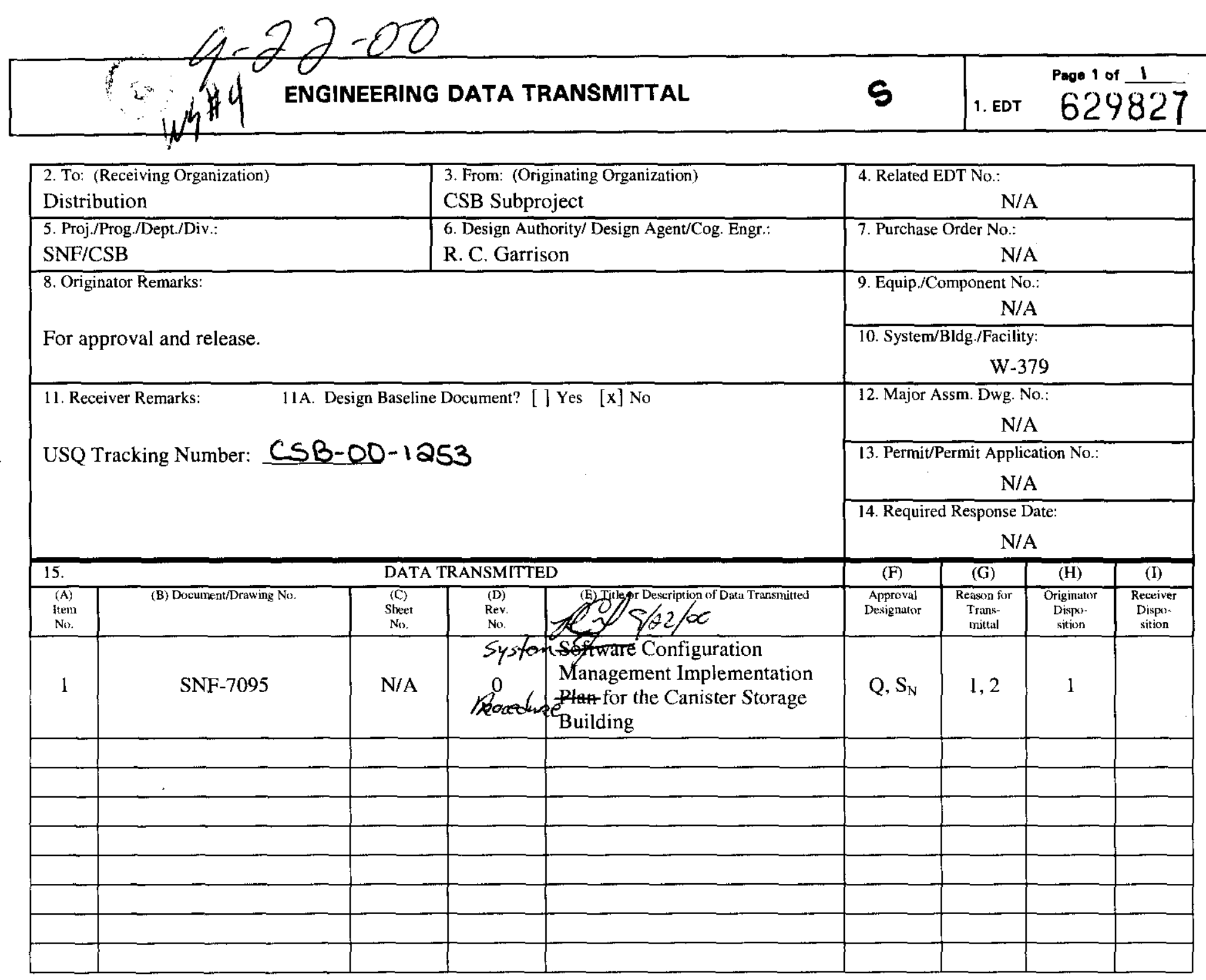

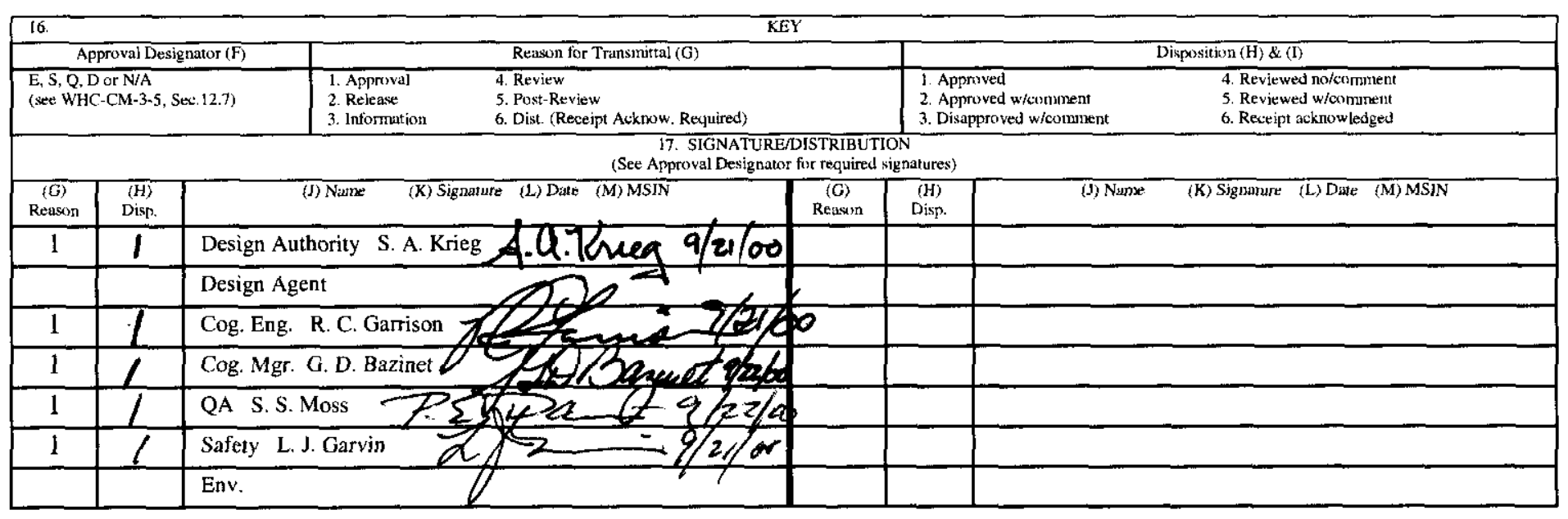

\begin{tabular}{|c|c|c|c|c|}
\hline 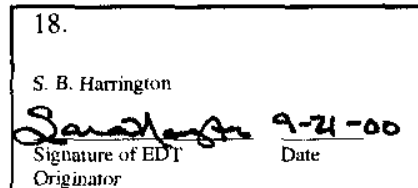 & $\begin{array}{l}19 . \\
\text { N/A } \\
\begin{array}{c}\text { Authorized Representativive } \\
\text { for Receving Organizution }\end{array}\end{array}$ & Date & 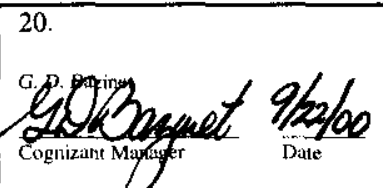 & $\begin{array}{l}\text { 21. DOE APPROVAL (if required) } \\
\text { Ctrl. No. } \\
\text { [] Approved } \\
\text { [] Approved w/comments } \\
\text { [] Disapproved w/comments }\end{array}$ \\
\hline
\end{tabular}

BD-7400-172-2 (05/96) GEF097 
SNF-7095

Revision 0

\section{System Configuration Management Implementation Procedure for the Canister Storage Building}

Prepared for the U.S. Department of Energy

Assistant Secretary for Environmental Management

Project Hanford Management Contractor for the

U.S. Department of Energy under Contract DE-AC06-96RL13200

Fluor Hanford

P.O. Box 1000

Richland, Washington 
S RNF-7095

EDT 629827

\section{System Configuration Management Implementation Procedure for the Canister Storage Building}

Project No: W-379

Document Type: IP

Division: SNF

R. C. Garrison

CE\&ES

Total Pages: 24

Date Published

September 2000

Prepared for the U.S. Department of Energy

Assistant Secretary for Environmental Management

Project Hanford Management Contractor for the

U.S. Department of Energy under Contract DE-AC06-96RL13200

Fluor Hanford

P.O. Box 1000

Richland, Washington
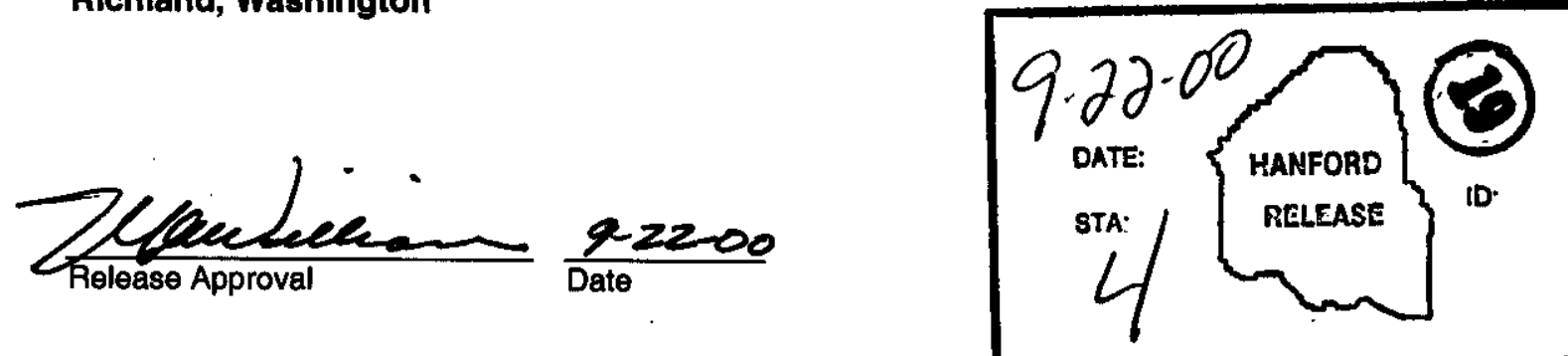
TRADEMARK DISCLAIMER

Reference herein to any specific commercial product, process,

or service by trade name, trademark, manufacturer, or

otherwise, does not necessarily constitute or imply its

endorsement, recommendation, or favoring by the United

States Government or any agency thereof or its contractors or subcontractors.

This report has been reproduced from the best available copy.

Printed in the United States of America 


\section{SYSTEM CONFIGURATION MANAGEMENT IMPLEMENTATION PROCEDURE FOR THE CANISTER STORAGE BUILDING}

\section{TABLE OF CONTENTS}

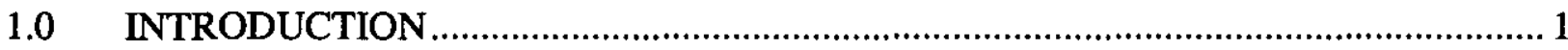

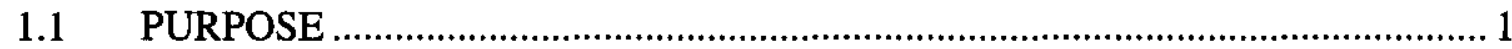

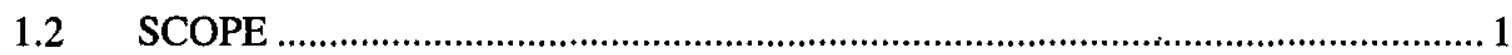

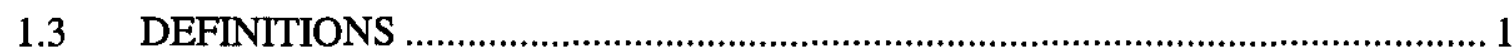

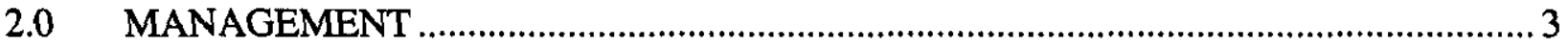

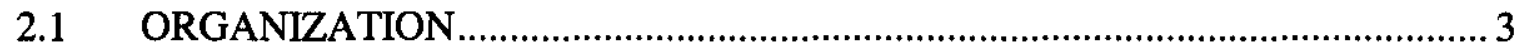

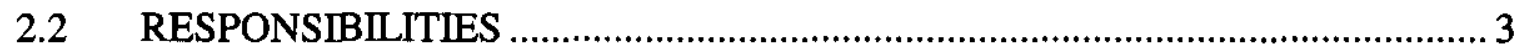

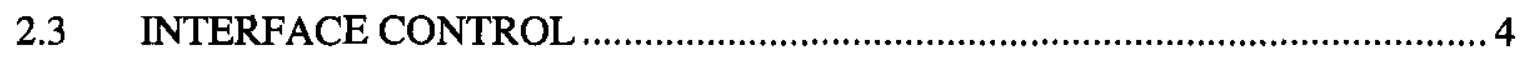

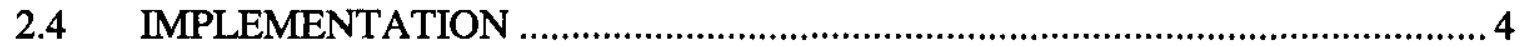

3.0 SYSTEM CONFIGURATION MANAGEMENT ACTIVITIES ……………................ 5

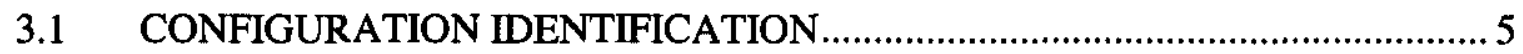

3.1.1 Application Software............................................................................ 5

3.1.2 Validation and Verification .................................................................... 6

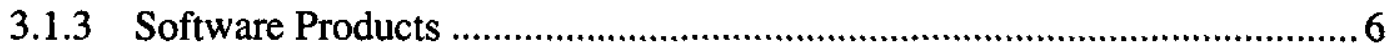

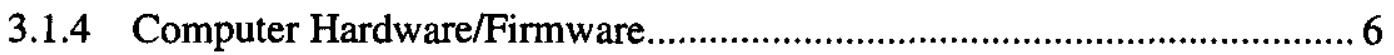

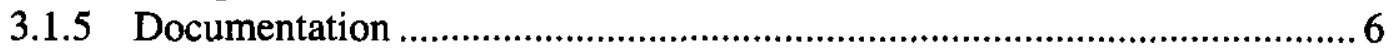

3.1.6 Removable Media …….....................................................................

3.1.7 Directory Nomenclature ……….......................................................... 7

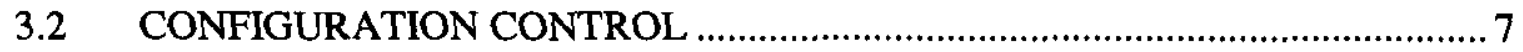

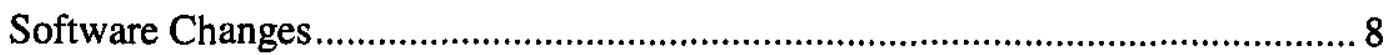

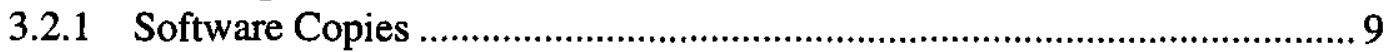

3.3 CONFIGURATION STATUS ACCOUNTING …….................................... 10

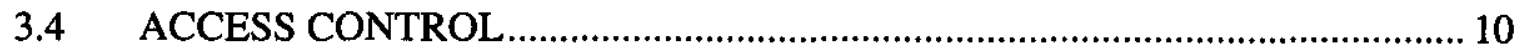

$3.5 \quad$ BACKUP AND RECOVERY ……................................................................. 10

4.0 TOOLS, TECHNIQUES, AND METHODOLOGIES …….........................................

$4.1 \quad$ DEVELOPMENT TOOLS .......................................................................... 11

4.1.1 Distributed Control System (DCS) ........................................................ 11

4.1.2 Gaseous Effluent Monitoring System (GEMS-100) …….......................... 11

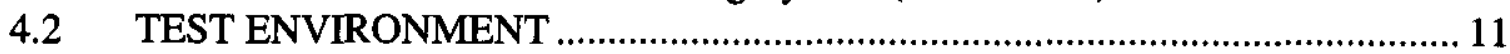

5.0 SUPPLIER CONTROL

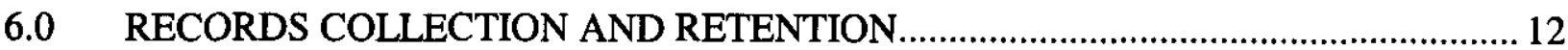

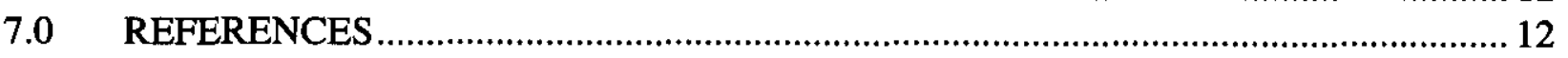

\section{LIST OF APPENDICES}

APPENDIX A Software Change Request or Problem Report Form ....................................... A-1

APPENDIX B Release Cover Sheet \& Revision Record Form and Instructions..................... B-1

APPENDIX C Software Change Request and Problem Report Form........................................ C-1 


\section{LIST OF TRADEMARKS}

Modsoft ${ }^{\mathrm{TM}}$ is a registered trademark of Gould, Inc., Rolling Meadows, Illinois.

Modbus Plus ${ }^{\mathrm{TM}}$ is a registered trademark of Gould, Inc., Rolling Meadows, Illinois.

FIX $32^{\mathrm{TM}}$ is a registered trademark of Intellution, Inc., Norwood, MA.

Windows NT ${ }^{\mathrm{TM}}$ is a registered trademark of Microsoft Corporation, Redmond, Washington.

GEMS- $100^{\mathrm{TM}}$ is a registered trademark of Nuclear Research Corporation, Warrington, PA.

RADACS $^{\mathrm{TM}}$ is a registered trademark of Nuclear Research Corporation, Warrington, PA.

DOS $^{\mathrm{TM}}$ is a registered trademark of Microsoft Corporation, Redmond, Washington.

Key Words: CSB, DCS, GEMS-100, Software, Configuration Control

Abstract: This document implements the procedure for providing configuration control for the monitoring and control systems associated with the operation of the Canister Storage Building (CSB). It identifies and defines the configuration items in the monitoring and control systems, provides configuration control of these items throughout the system life cycle, provides configuration status accounting, physical protection and control, and verifies the completeness and correctness of the items. It is written to comply with HNF-SD-SNF-CM-001, Spent Nuclear Fuel Configuration Management Plan (Forehand 1998), HNF-PRO-309, Computer Software Quality Assurance Requirements, HNF-PRO-2778, IRM Application Software System Life Cycle Standards, and applicable sections of administrative procedure AP-CM-6-037-00, SNF Project Process Automation Software and Equipment Configuration Management. 


\subsection{INTRODUCTION}

\subsection{PURPOSE}

The purpose of this document is to establish the Software Configuration Management Implementation Plan (SCMIP) for the Canister Storage Building (CSB). This procedure provides configuration management for the DCS and Computer Subsystems at the CSB.

The DCS monitors process parameters. The Gaseous Effluent Monitoring System (GEMS-100) monitors stack radiological effluent; logs stack effluent; and alarms locally and at the DCS. This SCMIP identifies and defines the configuration items in the CSB control and monitoring systems, and provides configuration control throughout the system life cycle, provides configuration status accounting, physical protection and control, and verifies the completeness and correctness of these items.

\subsection{SCOPE}

This procedure applies to the DCS, and the GEMS- $100^{\mathrm{TM}}$ software. The GEMS- $100^{\mathrm{TM}}$ is an independent system that is monitored by the DCS. Other inputs to the DCS are from individual field components.

The DCS software configuration was tested for validation and verification (V\&V). The GEMS$100^{\mathrm{TM}}, \mathrm{RADACS}^{\mathrm{TM}}, \mathrm{FIX}^{\mathrm{TM}} 2^{\mathrm{TM}}$, and Modsoft ${ }^{\mathrm{TM}}$ development software $\mathrm{V} \& \mathrm{~V}$ is not covered by this SCMIP.

\subsection{DEFINITIONS}

Configuration Item: Components of a software system requiring configuration control including software, documentation, hardware and operating environment. Note: The hardware referred to here include those portions of the operating environment necessary to assure continued operation of the software.

Configuration Management (CM): An integrated management process that applies technical and administrative direction and surveillance to identify and document the functional and physical characteristics of a facility/configuration item such that design requirements, documentation, systems and components match throughout the life of a facility/configuration item. Configuration management controls changes to these items, and records and reports change processing and implementation.

Production: Pertaining to the status of a given system following acceptance by the customer, i.e. the production phase (refer to HNF-PRO-2778, IRM Application Software System Life Cycle Standards).

Software Configuration Management (SCM): Configuration management applied to SNF Project process monitoring/control software and documentation to provide for the identification, change control, corrective actions, and configuration status of software for activities including design calculations, operational control and/or laboratory analysis. 
Software Change Request and Problem Report (SCR/PR): A document used to identify proposed changes to or suspected problems with the software. An SCR/PR may identify a new function, modify an existing function, or report suspected problems of the software.

Software Configuration Management Tool: Software product providing a centralized process to the PHMC for software configuration management. This is provided by Mortice Kern Systems, Inc. (MKS) Source Integrity configuration management system, and is managed by the Configuration Management Administrator.

Testing - Pertaining to the status of a given system prior to acceptance by the customer, i.e. the implementation phase. 
SNF-7095 REV 0

\subsection{MANAGEMENT}

\subsection{ORGANIZATION}

Design Authority - responsible for the Distributed Control System. Ensures monitoring system changes meet design basis.

System Cognizant Engineer - approves software changes, provides functional requirements and support for the system.

Automation/Software Engineer - evaluates and implements changes resulting from change requests.

Configuration Management Administrator - maintains media, security and change status in accordance with AP-CM-6-037 and this SCMIP.

\subsection{RESPONSIBILITIES}

Individuals assigned the following roles will be designated by the SNFP Facility Engineering Manager and approved by the Chief Engineer. Current designations will be listed in the change status log maintained by the System Cognizant Engineer, or delegate.

Design Authority - review and approve software changes. Ensures that configuration management controls are implemented, determines the need for and extent of software/system development, ensures appropriate review and approval of changes, and ensures configuration is compliant with design baseline and safety basis.

System Cognizant Engineer - approval of all software change requests and testing of changes prior to installation.

Automation/Software Engineer - evaluates, tests and implements software changes. Updates system documentation. Maintains system data directory, updates of system documentation and stores copies of backup media until acceptance and process testing of the system has been completed. Once this occurs, the system will be completed and the software transferred to the system owner.

Software Configuration Administrator - responsible for configuration management; provides configuration control and security of the system utilizing Mortice Kern Systems, Inc. (MKS) Source Integrity configuration management system, and this SCMIP; approves, implements and tracks configuration change status; and maintains software directory and backup media. 


\subsection{INTERFACE CONTROL}

The DCS is a process-monitoring tool only. Two remote termination units (RTUs), including PLCs, receive data from field devices and subsystems. The two NT production workstations are connected to HLAN for clock synchronization and future remote process monitoring capability.

The GEMS-100 ${ }^{\mathrm{TM}}$ includes field devices for input and provides feedback to effluent stack fan controls and local alarm annunciation. The monitoring system maintains a record copy of data for environmental reporting to Washington State Department of Ecology. Effluent radiation readings, alarm trips and system trouble alarms are transmitted to the DCS for control room annunciation.

\subsection{IMPLEMENTATION}

This SCMIP becomes effective when this procedure is approved and released. Responsibility for the SCM activity rests with the Configuration System Administrator as described in Section 2.2. Version change control is the method of providing configuration management of the CSB Control Systems software. 


\subsection{SYSTEM CONFIGURATION MANAGEMENT ACTIVITIES}

Configuration Management will be applied to the CSB DCS and subsystems as described in this section.

\subsection{CONFIGURATION IDENTIFICATION}

\subsubsection{Application Software}

Documentation used as guidance for configuration of CSB PLCs is found in the system description SNF-6151, Spent Nuclear Fuel Project Canister Storage Building System Design Description (Swenson, 2000); HNF-SD-WM-SAR-062, CSB Safety Analysis Report, Fluor Hanford, Inc., Richland, Washington; and AP-CM-6-37-00, Process Automation and Equipment Configuration Management procedure.

Additional documentation used as guidance for configuration of DCS PLCs is found in the system description, SNF-6690, Description Of The CSB Distributed Control System PLC Plus (PLCS-CSBSDD-001-R0) (Bazinet, 2000).

Additional documentation used as guidance for configuration of GEMS-100 ${ }^{\mathrm{TM}}$ is found in, SNF-6024, CSB GEMS-100 (V1) Stack Emissions Alarm Setpoints (Turnbaugh, 2000); W379-1289, HVAC Stack Monitoring System/DCS Interface (Finch, 1998)

The DCS PLC software code is developed using Modsoft ${ }^{\mathrm{TM}}$ Version 2.33 software on an NT workstation. Modsoft ${ }^{\mathrm{TM}}$ communicates directly with the Programmable Logic Controller (PLC). Developed software can be archived, downloaded, uploaded, and diagnosed at an NT workstation connected to PLCs in the RTU cabinets via Modbus Plus ${ }^{\mathrm{TM}}$ data highway architecture and communication protocol.

The Human Machine Interface (HMI) for the DCS by Intellution is FIX32 $2^{\mathrm{TM}}$ Version 6.12. This software is Windows based and developed on an NT workstation and downloaded to both Workstations.

The GEMS $-100^{\mathrm{TM}}$ (V1) firmware is running local to the GEMS-100 ${ }^{\mathrm{TM}}$ control cabinet on a proprietary EPROM and motherboard.

The data management software for GEMS-100 ${ }^{\mathrm{TM}}$ is the Radiological Assessment Display and Control System (RADACS) ${ }^{\mathrm{TM}}$ Version 2.0.4 and is a DOS ${ }^{\mathrm{TM}}$ based program. This software is configured and run on a PC (laptop). The laptop is connected to GEMS-100 ${ }^{\mathrm{TM}}$ via serial cable.

Each version (new or revised) of a production software release shall be a grouping of the software code (logic) and executables, documentation and any modifications to vendor software (e.g., configurations, etc.). The release is assigned a unique release number by the Automation/Software Engineer. In the case of new versions, the version number and modifications thereto will be noted. Refer to the sample form in the "Release Cover Sheet and Revision Record," Appendix B. The 
release form shall also note operating system and development tool revision numbers in Section 7 of that form.

\subsubsection{Validation and Verification}

Validation and verification of the CSB DCS software was performed and the test results are reported in SNF-6689, Test Results Report of the CSB DCS Acceptance Test Procedure PLC Plus (PLCSCSB-FAT-001-R0) (Bazinet, 2000); SNF-6688, CSB DCS Construction Acceptance Test Procedure PLC Plus (PLCS-CSB-CAT-001-R0) (Bazinet, 2000).

Validation and verification of the CSB GEMS- $100^{\mathrm{TM}}$ (V1) firmware and RADACS ${ }^{\mathrm{TM}}$ software was performed and the test results are reported in TP-201689, Functional Test Procedure for Gaseous Effluent Monitoring System GEMS-100 (V1) (Gomeringu, 1998); SNF-W379-PAT-010-1, SNF Project Facility/System Start-up Preoperational Acceptance test HVAC Stack Monitoring System (Jablonski, 1998).

\subsubsection{Software Products}

Each software product (e.g., the application software development packages, the operating system software, etc.) is assigned a unique product name and release version number by the appropriate vendor and will be used as identification as far as practicable on the software release documentation.

\subsubsection{Computer Hardware/Firmware}

Microprocessor controlled hardware, such as installed field components, modules, power supplies, etc., is controlled by normal Hanford administrative procedures [e.g., $\mathrm{H}-2$ or H-1 drawing system via Engineering Data Transmittals (EDT) and Engineering Change Notices (ECN)]. Configuration control is required by this SCMIP, only for the case of:

1) Identification of the minimum equipment necessary for operation, and

2) Evaluation of impacts caused by field hardware changes that are part of the design basis documentation set - via an SCR/PR.

\subsubsection{Documentation}

When a new or revised version of CSB software is released, the Automation/Software Engineer will: 1) establish a file with a copy of the information related to that release, and 2) prepare an SNF document to formally document the release. These documents are controlled by normal SNF administrative procedures (via ECN's or release/revision sheets). A sample of the release/revision sheet is shown in Appendix B. The new or revised release document incorporates SCR/PR's associated with the previous software version to provide backward traceability. Completed SCR/PR forms and the release document shall be returned to the Software Configuration Administrator for entry into the MKS System, and a copy kept in the local Document Control (DC) system and in log form by the Automation/Software Engineer. 


\subsubsection{Removable Media}

The Software Configuration Administrator shall maintain custody of removable media and verifies that it is correctly labeled, maintains backup copies, and maintains tracking documentation. Removable media will have the following information records on the label:

- Media identifier (i.e., disc number)

- Software identification

- Software revision identification ("R.r", "R" = major and "r" = minor software changes, e.g., 1.0)

- Software or data name or description

- Responsible organization and software custodian's name

- Recording date and time

\subsubsection{Directory Nomenclature}

Original or backup source and executable software placed on media containing multiple versions/revisions shall be segregated using the available directory/subdirectory structure.

The Software Configuration Administrator shall verify that the correct software component and version is installed on each computer, PLC or module. On the production systems, only the most current version will be maintained in a single project directory. For the DCS RTUs, the configuration is stored in the Modicon PLC memory. For the DCS HMI, the configuration is stored in the FIX $32^{\mathrm{rM}}$ program directory on both NT workstations. For the GEMS-100 ${ }^{\mathrm{rM}}$, the configuration is stored in the GEMS $100^{\mathrm{TM}}$ EPROM. For the GEMS $100^{\mathrm{TM}}$ data management software, the configuration is stored in the RADACS ${ }^{\mathrm{TM}}$ program directory on the PC laptop.

\subsection{CONFIGURATION CONTROL}

The Configuration Management Administrator utilizing the Mortice Kern Systems (MKS) Source Integrity configuration management system, and this SCMIP shall manage configuration control of the CSB software. The MKS system will be used to implement and track configuration change status, maintain a software directory and provide software media backups.

Change control will be managed via SNF document change requirements (ECN's, SCR/PR forms, release/revision sheets, EDT's, etc.) as noted in, 3.1.5 above.

SCR/PR approvals are recorded and submitted using the SCR/PR form. See Appendix A for an example of the form.

E-mail approvals for processing SCR/PR's may be substituted for handwritten approvals. When email approvals are used a copy of the e-mail approval must be attached to the SCR/PR.

Telephone approvals for processing SCR/PR's may be used, but subsequently must be documented on the SCR/PR form. 


\section{SNF-7095 REV 0}

\section{Software Changes}

Changes to the CLS Control Systems software will be processed as described in this section.

\begin{tabular}{|c|c|}
\hline $\begin{array}{l}\text { Anyone in owner/operator } \\
\text { organization }\end{array}$ & $\begin{array}{l}\text { Prepare a SCR/PR to identify a problem with or request a change to the software. } \\
\text { Forward the SCR/PR to the System Cognizant Engineer. Include recommendations on how } \\
\text { to implement changes where appropriate. }\end{array}$ \\
\hline Design Authority & $\begin{array}{l}\text { Ensures the change is compliant with the design baseline and Safety Basis, and approves } \\
\text { design baseline documents. }\end{array}$ \\
\hline $\begin{array}{l}\text { System Cognizant Engineer } \\
\text { (or delegate) }\end{array}$ & $\begin{array}{l}\text { Ensures that an evaluation is performed to determine if software changes would result in } \\
\text { potential changes to the design basis documentation (via an SCR/PR and attached ECN } \\
\text { with USQ review). } \\
\text { Determine which SCR/PR's are appropriate and forward to the Software Engineer for } \\
\text { analysis and hours estimate. } \\
\text { Determine whether the change is an emergency or routine SCR/PR. } \\
\text { Assign an SCR/PR Number and enter in the SCR/PR Log (Appendix C). }\end{array}$ \\
\hline $\begin{array}{l}\text { Automation/Software } \\
\text { Engineer }\end{array}$ & $\begin{array}{l}\text { Analyze SCR/PR and estimate hours and impact to complete and implement. } \\
\text { Evaluate SCR/PR and decide to accept, modify, reject or defer. Determine if SCR/PR } \\
\text { requires a major or minor revision. } \\
\text { Prioritize accepted SCR/PR's. Group one or more SCR/PR's into a planned release. } \\
\text { Plan with System Cognizant Engineer (or delegate) how, and to what extent changes to the } \\
\text { software will be tested and documented. } \\
\text { Forward appropriate problem reports (SCR/PR's) to vendor if it is a problem with the } \\
\text { vendor's product. } \\
\text { Perform the work identified in SCR/PR and conduct tests. Ensure that changes that cannot } \\
\text { be tested in a test environment are conducted in a manner that will not have adverse affect } \\
\text { on the software production environment. } \\
\text { Evaluate the results of the tests with Independent Reviewers: e.g., the System Cognizant } \\
\text { Engineer (or delegate), etc. to determine if the changes (individually and as a whole) are } \\
\text { acceptable for a production release. } \\
\text { Document test results and include with change request, or indicate supporting document } \\
\text { number if applicable. Obtain independent review. } \\
\text { Provide change documentation to Software Configuration Administrator. } \\
\text { Schedule implementation with the System Cognizant Engineer (or delegate) and with users } \\
\text { of the system. } \\
\text { Place source code and executable files for the release on removable media, labeled per } \\
\text { Section } 3.1 .6 \text {. }\end{array}$ \\
\hline
\end{tabular}




\begin{tabular}{|l|l|}
\hline & $\begin{array}{l}\text { Provide the removable media to the Software Configuration Administrator for entry into the } \\
\text { MKS software configuration management system. } \\
\text { Prepare and issue release documentation as an ECN, or as Release/Revision Record. } \\
\text { Update system documentation as required and place copies in the system project file. } \\
\text { Maintain the SCR/PR Log sheets in the project file. }\end{array}$ \\
\hline $\begin{array}{l}\text { Software Configuration } \\
\text { Administrator }\end{array}$ & $\begin{array}{l}\text { Verifies signatures on documentation. } \\
\text { Verifies removable media are properly labeled. } \\
\text { Enters the software release into the MKS software configuration management system. The } \\
\text { MKS system compares the new version against the previous version and archives the source } \\
\text { file and all revisions. }\end{array}$ \\
\hline $\begin{array}{l}\text { Verify that SCR/PR closeout is distributed to the initiator and others as appropriate. } \\
\text { Manager }\end{array}$ & \begin{tabular}{l} 
Maintains a configuration status log. \\
\hline
\end{tabular} \\
\hline
\end{tabular}

\subsubsection{Software Copies}

Software will be controlled in four locations as follows:

- Production Copy - latest release stored and operating on the production equipment.

- Working Copy - removable media used to transfer latest changes to the Production Copy used by the Automation/Software Engineer, administered by the Software Configuration Administrator.

- Master Copy - controlled copy archived and accessed on the MKS System, each major and minor release, labeled by Software Configuration Administrator. Working copies made from this copy for updating/changing/restoring the production copy.

- Backup Copy - duplicate of each master copy stored on the backup server in directories named to correspond to the removable media release numbers. 


\subsection{CONFIGURATION STATUS ACCOUNTING}

The configuration status of all controlled items is shown on the Release Cover Sheet (example, Appendix B). In addition, the status of all SCR/PR's and associated releases will be tracked and maintained, and be available on the backup directory as a $\log$ file, and in the MKS software configuration management system.

\subsection{ACCESS CONTROL}

Limiting access control through the use of restricted entry and passwords provides security for the CLS Control Systems software. The System Cognizant Engineer, or delegate provides an authorized user list and associated privilege levels. Authorized users are required to provide a user name and password.

\subsection{BACKUP AND RECOVERY}

Backup of the source code and executable files that constitute each production release is done by the Automation/Software Engineer onto the fileserver backup partition selected and documented by the Software Configuration Administrator at the time of release. The Software Configuration Administrator is responsible for verifying that the backup is in place and the appropriate files exist.

Recovery shall be accomplished by rewriting the appropriate files from the master media onto the production system. The Software Configuration Administrator or Automation/Software Engineer shall accomplish this as needed. Should the master media be simultaneously corrupt, recovery shall be from the MKS software configuration management system. 


\subsection{TOOLS, TECHNIQUES, AND METHODOLOGIES}

\subsection{DEVELOPMENT TOOLS}

\subsubsection{Distributed Control System (DCS)}

Working copies of Modsoft ${ }^{\mathrm{TM}}$, and FIX32 ${ }^{\mathrm{TM}}$ software are loaded on applicable workstations. Refer to vendor information on operation and use of these products.

Modicon Modsoft ${ }^{\mathrm{TM}}$ software does not have a simulation feature, but since this is a monitoring system, installing it on the NT workstations and verifying displays directly during calibration of input devices verified software functionality. The PLC ladder logic can be viewed, edited, and saved on a workstation and later loaded onto the RTU PLCs. The logic is loaded via the Modbus Plus ${ }^{\mathrm{TM}}$ communications network. Once connected with the PLC, Modsoft ${ }^{\mathrm{TM}}$ permits live viewing, editing, and forcing of logic states. This facilitates troubleshooting, testing and debugging.

Intellution FIX $32^{\mathrm{TM}}$ is the software platform for configuring the HMI graphics (operator interface) and permits execution of the HMI application. This facilitates testing and debugging. The HMI application can be developed on a programmer workstation or one of the production workstations and transferred via magnetic medium to both production workstations.

\subsubsection{Gaseous Effluent Monitoring System (GEMS-100)}

A working copy of the RADACS ${ }^{\mathrm{TM}} \mathrm{DOS}^{\mathrm{TM}}$ based software is loaded on the workstation. A working copy of the GEMS-100 ${ }^{\mathrm{TM}}$ firmware is loaded on the GEMS-100 motherboard EPROM. Refer to vendor information on operation and use of this product.

The GEMS-100 ${ }^{\mathrm{TM}}$ and RADACS ${ }^{\mathrm{TM}}$ software does not have a simulation feature. This system hardware, firmware, and software was specifically designed and installed for this facility. Software $\mathrm{V} \& \mathrm{~V}$ was accomplished through factory and construction testing. The configuration can be viewed, edited, and saved on the production workstation.

\subsection{TEST ENVIRONMENT}

All CSB software modifications and enhancements will be evaluated and approved on site. The software shall be reviewed and the test results approved by the System Cognizant Engineer. The Responsible Manager shall approve the implementation; otherwise backups of the current approved software will be restored. Modifications and enhancements will be grouped logically into production releases. 


\subsection{SUPPLIER CONTROL}

The System Cognizant Engineer, or delegate will ensure that new releases of vendor application and system software are tested prior to being permanently placed in production. The System Cognizant Engineer, or delegate will also ensure that new releases are consistent with original testing and are satisfied that the software will perform all the required functions. Changes in vendor application and/or system software will be processed as a Software Change Request or Problem Report (SCR/PR) with the same approval requirements as a locally generated change.

The Automation/Software Engineer, or delegate will maintain a software project file or binder of all software-related project documentation, correspondence, and project-produced documents. Vendor provided materials and manuals will be maintained by the Software Configuration Administrator. This software project file or binder will maintain the most current version of all documents.

\subsection{RECORDS COLLECTION AND RETENTION}

The CSB Control Systems Software/Automation Engineer will process software development and maintenance records in accordance with HNF-PRO-2778, IRM Application Software System Life Cycle Standards (Appendix A, Sections 8 and 9) and AP-CM-6-037-00, Process Automation Software and Equipment Configuration Management. System documentation update records will be sent to the Software Configuration Administrator for inclusion in the MKS Source Integrity configuration management system for this project. These records include, at a minimum the SCR/PR $\log$ and SCR/PR form entries, copies of which will be kept by the Automation/Software Engineer, or delegate in local project files.

\subsection{REFERENCES}

AP-CM-6-037-00, Rev. 0, SNF Project Process Automation Software and Equipment, Fluor Hanford, Inc., Richland, Washington.

Forehand, G. D., 1998, SNF Configuration Management Plan, HNF-SD-SNF-CM-001, Revision 3, Duke Engineering Services Hanford, Richland, Washington.

HNF-PRO-309, Rev. 1, Computer Software Quality Assurance Requirements, Fluor Hanford, Inc., Richland, Washington.

HNF-PRO-2778, Rev. 0, IRM Application Software System Life Cycle Standards, Fluor Hanford, Inc., Richland, Washington.

HNF-SD-WM-SAR-062, CSB Safety Analysis Report, Fluor Hanford, Inc., Richland, Washington. 
SNF-7095 REV 0

APPENDIX A

SOFTWARE CHANGE REQUEST AND PROBLEM REPORT FORM 


\section{SOFTWARE CHANGE REQUEST OR PROBLEM REPORT}

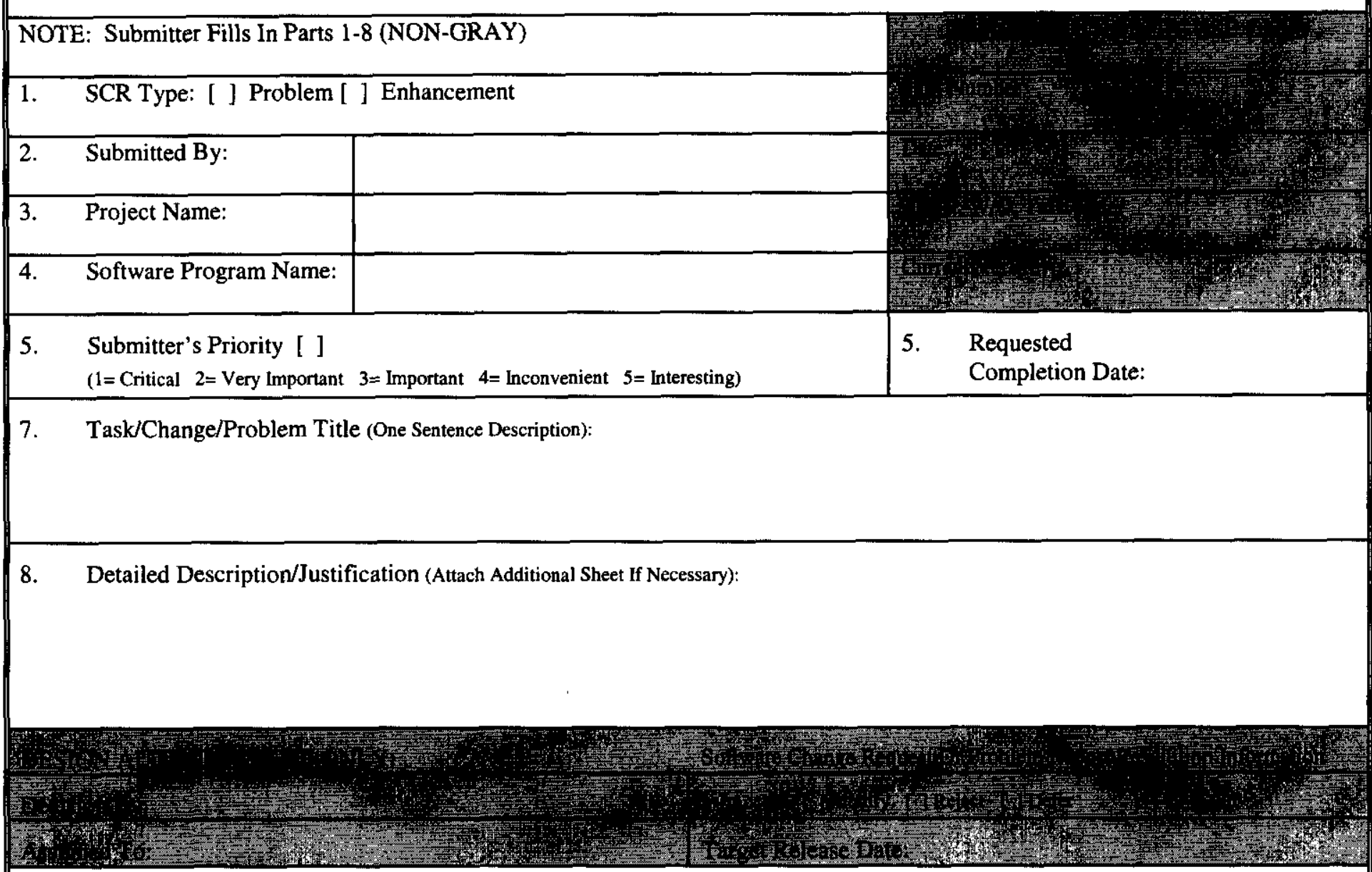

Solution Comments/Impact:

Software Programs, Modules or Files Affected:

\begin{tabular}{||l|l||}
\hline Task Completed By: & Date: \\
\hline Verified By: & Date: \\
\hline Actual Release Version: & Date: \\
\hline Closed By: & Date: \\
\hline
\end{tabular}




\section{Instructions for the Software Change Request or Problem Report}

These instructions are for preparing the Change Request or Problem Report. If more space is needed, use blank pages and attach them to the SCR/RP form. This will be the record of the change request or problem report.

Anyone may submit a Change Request or Problem Report:

1. Indicate if this is a problem report or request for enhancement.

2. Record the name of the person submitting the form and the date.

3. Enter 'System Name and Number' for project.

4. Enter 'System Name and Number' for software program name.

5. Record submitter's evaluated priority as shown.

6. Provide a requested completion date, or leave blank if unknown.

7. Provide a single sentence title or problem or enhancement.

8. Provide a description of the changes requested or the problems being reported. Provide justification if this is a change request. Attach additional sheets if necessary.

System Cognizant Engineer or Design Authority:

a. On receipt, enter the SCR/PR into the system log. Enter the SCR/PR number from the log on the SCR/PR form.

b. Enter the date received.

c. Enter the charge number if known, otherwise, leave blank.

d. Enter current Version/Revision of the product.

e. Review change request or problem with manager. Note that SCR/RP may require attached cost estimate and planning if extensive changes or testing are anticipated. Mark accept, modify, reject or defer as appropriate.

f. System Cognizant Engineer or Design Authority signs "decision by" block.

g. If accepted, assigns a Software Engineer and provides a Target Release Date as appropriate.

h. Software Engineer fills in solution, impacts and comments area, and identifies programs, modules and files to be affected. A list may be attached. Also documents/performs testing as required and attaches test results or additional verification documentation.

i. $\quad$ Software Engineer signs "Task Completed by" block and passes to independent reviewers.

j. Independent reviewer(s), at a minimum including the System Cognizant Engineer or Design Authority, signs "Verified By" block.

k. When included in a release, place release version in "Actual Release Version" block.

1. System Cognizant Engineer or Design Authority signs "Closed By" block when complete or rejected. 
SNF-7095 REV 0

\section{APPENDIX B}

\section{RELEASE COVER SHEET \& REVISION RECORD FORM AND INSTRUCTIONS}




\section{RELEASE COVER SHEET \& REVISION RECORD}

1. Software ID (Name):

Rev.:

2. Release Type: [] Initial Release [ ] Change

[] App Des [] Sfty Cls

3. Abstract

4. Software Files (or attach directory listing)

5. Software files record storage media and location

\begin{tabular}{|c|c|c|c|}
\hline 6. Documentation & Title & Number & $\mathbf{R e v}$ \\
\hline \multicolumn{4}{|l|}{ Requirements } \\
\hline \multicolumn{4}{|l|}{ Design } \\
\hline \multicolumn{4}{|l|}{ Design Verif. } \\
\hline \multicolumn{4}{|l|}{ Validation } \\
\hline \multicolumn{4}{|l|}{ User } \\
\hline \multicolumn{4}{|l|}{ Config. Cntl. } \\
\hline 7. Environment & Description & $\operatorname{Rev}$ & IL/Safety Class \\
\hline \multicolumn{4}{|l|}{ Hardware } \\
\hline \multicolumn{4}{|l|}{ Oper. Software(s) } \\
\hline \multicolumn{4}{|l|}{ Language(s) } \\
\hline Comm. Networks & & & \\
\hline
\end{tabular}

8. Released for:

[ ] Integration [ ] Operational Test [] Operation

9. Approvals

Software Engineer:

Date

Design Authority:

Date:

Software Custodian:

Date: 


\section{Instructions for the Release Cover Sheet \& Revision Record}

Fill out as indicated:

1. Provide Software Name and new revision number.

2. Check release type. Indicate Approval Designator and Safety Class (SC, SS, GS).

3. Provide an abstract describing the product being released. Indicate if only a portion of the software is being modified.

4. List all source and executable files that are being released and where they reside. Attaching a directory listing is acceptable, if it includes the full names of the file, creation date and time (combination is version identification). Date on all files may be set to release date, time may be set to indicate the release version number (e.g. 2.07a).

5. Indicate source and executable file master type (floppy disk, optical, magnetic tape), media serial number and storage location. This media will be held by the software custodian.

6. List the documentation components for the release.

7. List the operational environment for the release.

8. Check the reason/limits for the release.

9. Provide approval signatures as required by SCMIP. 
SNF-7095 REV 0

\section{APPENDIX C}

\section{SOFTWARE CHANGE REQUEST AND}

PROBLEM REPORT LOG FORM 


\section{SOFTWARE CHANGE REQUEST AND PROBLEM REPORT LOG}

The Automation/Software Engineer should enter the next sequential number on the Log Form, enter the Task/Change/Problem Title from the SCR/PR form, and enter the SCR/PR number on the SCR/PR form.

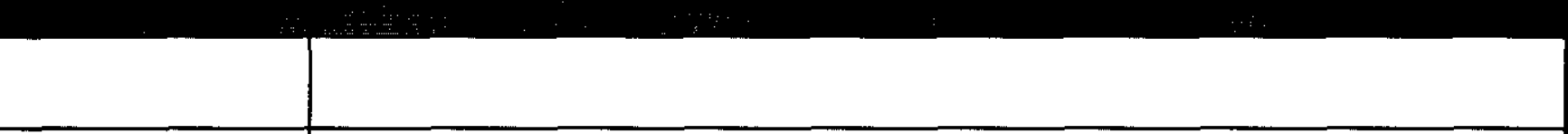

\begin{tabular}{|l|l|}
\hline & \\
\hline & \\
\hline & \\
\hline
\end{tabular}

